\title{
ORIGINAL
}

\section{EFEITO DA RESTRIÇÃO ENERGÉTICA NA ATIVIDADE HEPÁTICA DA GAMA-GLUTAMILTRANSPEPTIDASE E NOS NIVEIS DE GLUTATIONA'}

\section{EFFECT OF CALORIC RESTRICTION ON HEPATIC GAMMA-GLUTAMYL TRANSPEPTIDASE ACTIVITY AND ON GLUTATHIONE LEVELS}

\author{
Ida Maria VIANNA DE OLIVEIRA² \\ Roseane Harue Yoshida de PAULO ${ }^{3}$ \\ Elizabeth FUJIMORI²
}

\begin{abstract}
RESUMO
Avaliou-se o efeito da restrição energética aguda (crescimento pós-desmame) e crônica (lactantes desnutridas desde o período pré-natal e seus filhotes) na atividade da gama-glutamiltranspeptidase e nos níveis de glutationa. O consumo da dieta foi ad libitum (controle) ou com restrição de $30 \%$ (desnutrido), tendo-se conduzido dois ensaios, um de desnutrição aguda e outro de desnutrição crônica. A restrição aguda provocou redução significativa no ganho ponderal dos ratos em crescimento, mas as mães cronicamente desnutridas ganharam significativamente mais peso/filhote, pois apresentaram menor número de filhotes. Não foram observadas alterações significativas nos níveis de glutationa, na atividade da gama-glutamiltranspeptidase e mesmo na concentração de proteína hepática sob o efeito da restrição energética, aguda ou crônica. Menor desequilíbrio no perfil de aminoácidos plasmáticos e na síntese protéica, conseqüente à desnutrição energética e não à protéica, pode justificar estes resultados.
\end{abstract}

Termos de indexação: gama-glutamiltransferase, glutationa, desnutrição protéico-energética, crescimento, gravidez, lactação.

\section{SUMMARY}

The purpose of this study was to evaluate the effect of the acute (post-weaning growth) and chronic (lactating rats undernourished since prenatal period and their pups) caloric restriction on hepatic gamma-glutamyl transpeptidase activity and glutathione levels of rats. Diet consumption was either unrestricted (control group) or 30\% restricted (undernourished group).Two trials, one of acute malnutrition and another of chronic malnutrition, were conducted. Acute restriction caused significant reduction in the weight gain of the growing rats, but chronically undernourished mothers showed a significantly higher weight gain/pup, since they presented fewer pups. No significant alterations in glutathione levels, gamma-glutamyl transpeptidase activity, or even in the hepatic protein concentration were observed under acute or chronic caloric restriction. The less pronounced unbalance in the profile of plasmatic amino acids and in the protein synthesis (consequence of caloric, rather than protein malnutrition) can justify such results.

Index terms: Gamma-glutamyltransferase, glutathione, protein-energy malnutrition, growth, pregnancy, lactation.

\footnotetext{
1) Pesquisa parcialmente financiada pela Fundação de Auxílioà Pesquisa de São Paulo (FAPESP), Processo n. 95/0825-0.

(2) Departamento de Enfermagem em Saúde Coletiva, Escola de Enfermagem, Universidade de São Paulo. Av. Dr. Enéas de Carvalho Aguiar, 419, Cerqueira César, 05403000, São Paulo, SP, Brasil. Correspondência para/Correspondence to: I.M.V. OLIVEIRA.

(3) Curso de Graduação em Enfermagem, Escola de Enfermagem, Universidade de São Paulo (Bolsista de Iniciação Científica da FAPESP, Processo n. 95/0543-4).
} 


\section{INTRODUÇÃO}

Estudos anteriores têm demonstrado uma elevação na atividade sérica e hepática da enzima $\gamma$-glutamiltrans- peptidase (EC 2.3.2.2 - GGT) em ratos jovens submetidos a dietas restritas em proteína e, sobretudo, deficientes em aminoácidos sulfurados (Vianna de Oliveira \& de Angelis, 1996a; Vianna de Oliveira et al., 1998a; Vianna de Oliveira et al., 1998b; Vianna de Oliveira et al., 1999).

Sabe-se que a GGT é uma glicoproteína ligada à membrana celular responsável por catalisar a reação de grupos glutamil, entre eles a glutationa, com qualquer dos inúmeros aminoácidos, possibilitando sua captação e transporte (Meister, 1973). Também é responsável pela degradação da glutationa, podendo torná-la disponível como fonte de cisteína para síntese protéica, sobretudo de albumina (Tateishi et al., 1974; Tateishi et al, 1977).

A glutationa $(\mathrm{GSH})$ é um tripeptídeo ( $\gamma$-glutamil-cisteinil-glicina) que tem como funções a manutenção da atividade celular, a detoxificação de compostos xenobióticos e a ação contra radicais livres (Comporti et al., 1991).

Tem sido constatada uma relação entre o aumento na atividade da GGT e a redução nos níveis hepáticos de GSH com a desnutrição protéica em ratos durante os períodos de crescimento e de lactação (Vianna de Oliveira \& de Angelis, 1996a; Vianna de Oliveira \& Fujimori, 1996b; Vianna de Oliveira et al., 1998a; Vianna de Oliveira et al., 1998b).

A diminuição do GSH hepático durante a restrição protéica na fase de crescimento, em conseqüência do aumento na atividade da GGT, foi revertida após a suplementação protéica com metionina, tendo elevado os níveis de GSH e reduzido a atividade da enzima (Hum et al., 1992; Goss et al., 1994; Vianna de Oliveira et al., 1998a; Vianna de Oliveira et al., 1998b; Vianna de Oliveira et al., 1999).

É conhecido o desequilíbrio causado pela desnutrição protéica, em função da reduzida disponibilidade de aminoácidos essenciais para a síntese de proteínas, expresso em alterações metabólicas que incluem a hipoalbuminemia (Coward et al., 1977; Smith \& Lunn, 1984).

Entretanto, a restrição apenas energética poderia ser acompanhada de respostas metabólicas menos acentuadas, resultando em menor desequilíbrio fisiológico (Coward et al., 1977; Smith \& Lunn, 1984). Assim, não se observaram variações significativas na atividade de enzimas e hormônios em modelos experimentais de "marasmo" como as obtidas com modelos de desnutrição protéica (Atinmo et al., 1978).
Este trabalho tem como finalidade avaliar em ratos, durante períodos de intenso desenvolvimento fisiológico, se o efeito da desnutrição energética na concentração de GSH e na atividade hepática da GGT será similar ao observado em ensaios de restrição protéica.

\section{MATERIAL E MÉTODOS}

Delineamento experimental: foram desenvolvidos dois ensaios para verificar o efeito tanto da desnutrição energética aguda como crônica nos processos metabólicos envolvendo a GGT e o GSH em diferentes etapas de crescimento pós-natal:

- Ensaio 1: efeito da restrição energética aguda: aproximadamente 20 ratos foram submetidos à restrição energética durante a fase de crescimento linear pósdesmame, em um período experimental de 21 dias.

- Ensaio 2: efeito da restrição energética crônica: um total de 18 fêmeas foram mantidas desde a concepção até a idade adulta (incluindo os períodos: pré-natal, pós-natal e crescimento, num total de 188 dias) sob dieta adequada ou restrita em energia (30\% em relação ao grupo controle), para se obter o efeito da desnutrição crônica na primeira geração (mães) e na segunda geração (filhotes). Foi, então, estudado o efeito da continuidade da restrição energética durante o período de gestação (21 dias) incluindo o pico da lactação (15 dias), totalizando 37 dias de experiência. Ao término do ensaio foram sacrificados as mães e 2 filhotes machos, estes com pesos dentro da média e desvio-padrão calculados para o total de machos.

Dieta e tratamento dos animais: utilizaram-se ratos (Rattus norvergicus de origem Wistar) machos com cerca de 30 dias de idade (Ensaio 1) e fêmeas primíparas adultas de 166 dias de idade (Ensaio 2), todos provenientes de colônia fechada out bread, mantida no biotério do Laboratório de Nutrição da Escola de Enfermagem da Universidade de São Paulo. Os animais foram selecionados por peso e alimentados com ração comercial marca Labina para roedores ${ }^{4}$. Foram distribuídos em dois lotes: Lote-controle, cujo consumo foi ad libitum e Lote-experimental, com consumo de $70 \%$ em relação ao controle e alojados individualmente nas mesmas condições ambientais quanto à iluminação (ciclo de $12 \mathrm{~h}$ claroescuro) e à temperatura (mantida a $25^{\circ} \mathrm{C}$ ). Todos os animais receberam água ad libitum. O controle do peso corporal e do consumo de ração e água foram diários durante os diferentes períodos experimentais estabelecidos para os dois ensaios.

Obtenção do material de ensaio: ao término de cada ensaio, os animais foram submetidos a ligeira analgesia com éter etílico e sacrificados por punção cardíaca. Para evitar possíveis variações circadianas, procedeu-se o sacrifício entre $10 \mathrm{~h}$ e $12 \mathrm{~h}$.

\footnotetext{
(4) Ração Labina, Ralston Purina do Brasil Ltda.
} 
Após remoção e limpeza em solução fisiológica gelada, os fígados foram pesados e homogeneizados.

Homogenização dos fígados: para as análises de GGT, amostras de fígado pesando aproximadamente 500 $\mathrm{mg}$ foram homogeneizadas em solução contendo manitol 0,21M, sacarose 0,07M e EDTA 0,1 mM ajustado a $\mathrm{pH}$ 7,4. As determinações de GSH foram efetuadas no sobrenadante ácido, obtido pela centrifugação (15000 x $\mathrm{g}$ por $10 \mathrm{~min}$ ) da mistura de igual volume de homogenato de fígado e ácido perclórico 1,2 $\mathrm{N}$ contendo $2 \mathrm{mM}$ de EDTA, conforme sugerido por Tateishi et al. (1974).

Determinação da atividade da GGT: a 0,05 $\mathrm{ml}$ de amostra adicionou-se $0,5 \mathrm{ml}$ de substrato contendo 100 $\mathrm{mM} / \mathrm{I}$ de tampão Tris-pH 8,25, $100 \mathrm{mM} / \mathrm{I}$ de glicilglicina, 2,9 $\mathrm{mM} / \mathrm{I}$ de L- $\gamma$-glutamil-3-carboxi-4-nitroanilida, de acordo com Szasz (1974). Após incubação a $37^{\circ} \mathrm{C}$ durante $45 \mathrm{~min}$, foram adicionados $2 \mathrm{ml}$ de ácido acético $1,1 \mathrm{~N}$, para o término da reação, conforme o proposto por Jacobs (1971) e modificado por Persijin et al. (1971). A leitura da p-nitroanilina formada durante o processo foi efetuada a 405 nm, após centrifugação por 10 min a 2000 rpm.

Determinação da glutationa reduzido: foi estimado pelo método de Saville (1958).

Determinação de proteína total: o conteúdo de proteína foi dosado pelo método de Lowry et al. (1951), tendo soroalbumina bovina como padrão.

Análise estatística dos dados: os procedimentos estatísticos incluíram teste " $t$ " pareado, análise de variância (ANOVA) e testes não paramétricos quando indicado (Wilcoxon e Kruskal-Wallis), utilizando-se os softwares Epi Info (Dean et al., 1997) para as análises e Dbase-plus para a construção do banco de dados.

\section{RESULTADOS}

Efeito da restrição energética aguda: ocorreu redução significativa do ganho ponderal e do peso do fígado dos ratos em crescimento submetidos à restrição energética em relação ao grupo controle (Tabela 1). A restrição energética não induziu alterações significativas ( $p>0,05)$ nos níveis de GSH, na atividade da GGT e na concentração de proteína hepática dos animais (Tabela 2).

Efeito da restrição energética crônica: as mães cronicamente restritas em energia iniciaram a gravidez com peso $25 \%$ menor em relação aos seus controles e mantiveram a diferença significativa do peso até o término da gestação; todavia ocorreu uma recuperação de peso durante o período gestacional e o percentual anterior foi reduzido para 7,3\% no pós-parto (Tabela 3 ).

Durante a lactação ocorreu em ambos os grupos uma depleção de peso materno, que foi mais acentuada nas mães desnutridas colocando a diferença de peso em relação às mães do lote controle em 16,6\%.

Analisando o ganho ponderal na gestação e lactação, nota-se que não houve diferença significativa entre as mães desnutridas e as do lote controle. Entretanto, as mães desnutridas ganharam significativamente mais peso/ filhote, uma vez que apresentaram um número de filhotes aproximadamente $21 \%$ menor $(p<0,05)$ em relação ao controle, tanto após o parto como após a lactação (Tabelas 4 e 5). Conseqüentemente, embora o peso da ninhada destas mães tenha se apresentado significativamente menor após a lactação, o peso médio de filhotes machos não diferiu significativamente do peso daqueles amamentados por mães-controle. Assim, a redução observada no número de filhotes e no peso das mães desnutridas foi considerada estratégica para a consecução do aleitamento dos filhotes sobreviventes porque não alterou significativamente seus pesos no $15^{\circ}$ dia de lactação. As mães com restrição energética crônica também apresentaram níveis de GSH significativamente mais elevados que as mães do lotecontrole.

\section{DISCUSSÃO}

A desnutrição energética aguda ou crônica não mostrou efeito significativo sobre a atividade da GGT e os

Tabela 1. Ensaio 1: Efeito de 21 dias de restrição energética aguda sobre o peso do fígado, o ganho ponderal e o consumo de alimentos de ratos machos em crescimento ${ }^{1}$.

\begin{tabular}{|c|c|c|}
\hline \multirow{3}{*}{ Variáveis } & \multicolumn{2}{|c|}{ Grupo desnutrido } \\
\hline & (consumo ad libitum) & (consumo restrito a $70 \%$ ) \\
\hline & $\bar{X} \quad$ DP & $\bar{x} \quad$ DP \\
\hline Peso inicial (g) & $46,2 \pm 4,3^{\mathrm{a}}$ & $46,4 \pm 5,8^{\mathrm{a}}$ \\
\hline Peso final (g) & $152,3 \pm 6,2^{\mathrm{a}}$ & $110,8 \pm 6,4^{b}$ \\
\hline Peso do fígado (g) & $8,2 \pm 0,4^{a}$ & $4,6 \pm 0,9^{b}$ \\
\hline Peso ganho (g) & $107,2 \pm 9,9^{\mathrm{a}}$ & $64,5 \pm 7,1^{b}$ \\
\hline Consumo (g/dia) & $17,2 \pm 1,2^{\mathrm{a}}$ & $11,9 \pm 0,0^{b}$ \\
\hline Consumo total (g) & $361,2 \pm 27,6^{\mathrm{a}}$ & $250,2 \pm 0,0^{b}$ \\
\hline
\end{tabular}

${ }^{(1)}$ Médias, na mesma linha, seguidas de letras iguais não diferem significativamente $(p \geq 0,05) . n \geq 6$ 
Tabela 2. Ensaio 1: Efeito de 21 dias de restrição energética aguda sobre a atividade da GGT e as concentrações de glutationa e proteína no fígado de ratos em crescimento ${ }^{1}$.

\begin{tabular}{|c|c|c|}
\hline \multirow{3}{*}{ Variáveis } & Grupo controle & Grupo desnutrido \\
\hline & (consumo ad libitum) & (consumo restrito a $70 \%$ ) \\
\hline & $\bar{x} \quad D P$ & $\bar{x} \quad$ DP \\
\hline Proteína (mg/g fígado) & $150,04 \pm 4,85$ & $148,78 \pm 3,60^{\mathrm{a}}$ \\
\hline GGT (U/g proteína) & $0,97 \pm 0,22$ & $0,93 \pm 0,20^{\mathrm{a}}$ \\
\hline $\mathrm{GSH}(\mu \mathrm{mol} / \mathrm{g}$ fígado) & $4,49 \pm 0,29$ & $4,39 \pm 0,51^{\mathrm{a}}$ \\
\hline
\end{tabular}

(1) Médias, na mesma linha, seguidas de letras iguais não diferem significativamente $(p \geq 0,05) \cdot \mathrm{n} \geq 6$

Tabela 3. Ensaio 2: Efeito da restrição energética crônica sobre o peso, a variação ponderal e o consumo alimentar durante a gestação (22 dias) e lactação (15 dias) de ratas adultas'.

\begin{tabular}{|c|c|c|c|c|}
\hline \multirow{3}{*}{ Variáveis } & \multicolumn{2}{|c|}{ Grupo controle } & \multicolumn{2}{|c|}{ Grupo desnutrido } \\
\hline & \multicolumn{2}{|c|}{ (consumo ad libitum) } & \multicolumn{2}{|c|}{ (consumo restrito a $70 \%$ ) } \\
\hline & $\bar{X}$ & DP & $\bar{x}$ & DP \\
\hline \multicolumn{5}{|l|}{ Peso (g) } \\
\hline Inicial & 217,50 & $\pm 7,80^{a^{*}}$ & $163,20 \pm$ & $\pm \quad 5,10^{b}$ \\
\hline Final & 283,30 & $\pm 24,20^{\mathrm{a}^{*}}$ & $240,10 \pm$ & $\pm 6,70^{b}$ \\
\hline Pós-Parto (PP) & 213,50 & $\pm 28,10^{\mathrm{a}}$ & $198,00 \pm$ & $\pm 12,30^{\mathrm{a}}$ \\
\hline Pós-Lactação (PL) & 199,60 & $\pm 4,00^{a^{*}}$ & $166,40 \pm$ & $\pm 14,80^{b}$ \\
\hline \multicolumn{5}{|l|}{ Variação ponderal } \\
\hline$\Delta \mathrm{G}^{2}$ & 65,70 & $\pm 17,20^{\mathrm{a}}$ & 76,80 & $\pm 8,00^{\mathrm{a}}$ \\
\hline$\Delta \mathrm{G} / \mathrm{n}$. filhotes & 6,00 & $\pm 1,40^{\mathrm{a}}$ & 9,20 & $\pm 1,90^{b}$ \\
\hline$\Delta \mathrm{PG}^{2}$ & $-4,00$ & $\pm 24,10^{\mathrm{a}^{*}}$ & 34,70 & $\pm 11,20^{b}$ \\
\hline$\Delta \mathrm{PL}^{2}$ & $-17,90$ & $\pm 3,80^{a^{*}}$ & $3,70 \pm$ & $\pm 13,30^{b}$ \\
\hline \multicolumn{5}{|l|}{ Consumo total (g) } \\
\hline Gestação & 411,40 & $\pm 30,40^{\mathrm{a}}$ & 270,30 & $\pm 12,50^{\mathrm{b}}$ \\
\hline Lactação & 509,50 & $\pm 28,10^{\mathrm{a}}$ & 354,30 & $\pm 16,50^{b}$ \\
\hline Consumo total & 921,00 & $\pm 44,80^{\mathrm{a}}$ & $624,60 \pm$ & $\pm 24,00^{b}$ \\
\hline Eficácia alimentar ${ }^{3}$ & 0,16 & $\pm 0,06^{\mathrm{a}}$ & $0,28 \pm$ & $\pm 0,01^{\mathrm{a}}$ \\
\hline
\end{tabular}

(1) Médias, na mesma linha, seguidas de letras iguais não diferem significativamente $\left(p>0,05\right.$ ou $\left.p>0,01^{*}\right) \cdot n \geq 6$

${ }^{(2)} \Delta \mathrm{G}=$ (Peso Final - Peso Inicial); $\Delta \mathrm{PG}=$ (Peso Pós-Parto - Peso Inicial); $\Delta \mathrm{PL}$ (Peso Pós-Lactação - Peso Inicial)

(3) Eficácia alimentar na gestação $=$ ganho em peso (g) consumo total alimento (g)

Tabela 4. Ensaio 2: Efeito da restrição energética crônica sobre o número e o peso ao nascer e pós-lactação dos filhotes de mães cronicamente desnutridas ${ }^{1}$.

\begin{tabular}{|c|c|c|}
\hline \multirow{3}{*}{ Variáveis } & Grupo controle & Grupo desnutrido \\
\hline & (consumo ad libitum) & (consumo restrito a $70 \%$ \\
\hline & $\bar{X} \quad$ DP & $\bar{x} \quad \mathrm{DP}$ \\
\hline \multicolumn{3}{|l|}{ Pós-nascimento } \\
\hline Peso ninhada (g) & $54,4 \pm 13,3^{\mathrm{a}}$ & $45,1 \pm 7,6^{\mathrm{a}}$ \\
\hline Número de filhotes & $11,0 \pm 2,0^{\mathrm{a}}$ & $8,7 \pm 2,0^{\mathrm{a}}$ \\
\hline Peso médio de filhotes machos (g) & $4,8 \pm 0,5^{\mathrm{a}}$ & $5,3 \pm 0,6^{\mathrm{a}}$ \\
\hline Número de filhotes machos & $6,0 \pm 2,7^{\mathrm{a}}$ & $4,0 \pm 1,3^{\mathrm{a}}$ \\
\hline \multicolumn{3}{|l|}{ Pós-lactação } \\
\hline Peso ninhada (g) & $179,3 \pm 5,9^{a}$ & $92,7 \pm 20,4^{b}$ \\
\hline Número de filhotes & $10,3 \pm 0,6^{\mathrm{a}}$ & $6,0 \pm 0,9^{b}$ \\
\hline Peso médio de filhotes machos (g) & $17,3 \pm 0,8^{\mathrm{a}}$ & $15,4 \pm 1,4^{\mathrm{a}}$ \\
\hline Número de filhotes machos & $4,7 \pm 2,5^{a}$ & $2,8 \pm 0,8^{\mathrm{a}}$ \\
\hline
\end{tabular}

(1) Médias, na mesma linha, seguidas de letras iguais não diferem significativamente $(p>0,05)$. $n \geq 6$ 
Tabela 5. Ensaio 2: Efeito da restrição energética crônica sobre a atividade da GGT e a concentração de GSH no fígado de mães e filhotes pós-lactação ${ }^{1}$.

\begin{tabular}{|c|c|c|}
\hline \multirow{3}{*}{ Variáveis } & Grupo controle & Grupo desnutrido \\
\hline & (consumo ad libitum) & (consumo restrito a $70 \%$ ) \\
\hline & $\bar{x} \quad$ DP & $\bar{x} \quad$ DP \\
\hline \multicolumn{3}{|c|}{ Proteína (mg/g fígado) } \\
\hline Mães & $268,26 \pm 37,42^{\mathrm{a}}$ & $283,47 \pm 26,47^{\mathrm{a}}$ \\
\hline Filhotes & $229,18 \pm 35,55^{\mathrm{a}}$ & $280,14 \pm 19,83^{\mathrm{a}}$ \\
\hline \multicolumn{3}{|c|}{ GGT (U/g proteína) } \\
\hline Mães & $1,74 \pm 0,29^{\mathrm{a}}$ & $1,78 \pm 0,32^{\mathrm{a}}$ \\
\hline Filhotes & $0,49 \pm 0,10^{\mathrm{a}}$ & $0,48 \pm 0,12^{\mathrm{a}}$ \\
\hline \multicolumn{3}{|c|}{ GSH $(\mu \mathrm{mol} / \mathrm{g}$ fígado $)$} \\
\hline Mães & $1,88 \pm 0,07^{\mathrm{a}}$ & $0,78 \pm 0,04^{b}$ \\
\hline Filhotes & $2,47 \pm 0,32^{\mathrm{a}}$ & $2,41 \pm 0,43^{\mathrm{a}}$ \\
\hline
\end{tabular}

(1) Médias, na mesma linha, seguidas de letras iguais não diferem significativamente $(p>0,05) . \mathrm{n} \geq 6$

níveis hepáticos de GSH, em relação aos animais controle com livre acesso à mesma dieta. Tanto as mães quanto os filhotes desnutridos não apresentaram a esperada elevação da GGT hepática e a redução do nível de GSH.

Estes resultados diferem daqueles obtidos com animais submetidos à desnutrição protéica na fase de crescimento ou durante a gestação-lactação que evidenciaram significativo aumento na atividade da enzima e diminuição na concentração de GSH (Vianna de Oliveira \& Fujimori, 1996a; Vianna de Oliveira \& de Angelis, 1996b; Vianna de Oliveira et al.,1998a; Vianna de Oliveira et al., 1998b; Vianna de Oliveira et al., 1999).

A distinta adaptação metabólica, representada por mudanças hormonais, enzimáticas e sobretudo por alterações na síntese protéica, em resposta à desnutrição protéica ou à desnutrição apenas energética poderia justificar estas desigualdades (Coward et al., 1977; Atinmo et al., 1978; Smith \& Lunn, 1984; Sainz et al., 1986).

A restrição protéica reduz a síntese, sobretudo de albumina, devido à baixa e desequilibrada disponibilidade de aminoácidos (Coward et al., 1977; Smith \& Lunn, 1984) suportando a hipótese de que cisteína poderia ser mobilizada do pool de GSH, o que resultaria em aumento de GGT e redução do tiol. Na má-nutrição energética, como a efetuada neste estudo, os níveis plasmáticos de aminoácidos essenciais e não essenciais poderiam ter permanecido inalterados e a síntese protéica não ter sido diretamente afetada, justificando a manutenção dos níveis de GSH e a atividade da GGT (Coward et al., 1977; Sainz et al., 1986).

É importante ressaltar que, apesar da concentração de GSH hepático não se alterar sob a restrição alimentar, foi significativa a sua redução quando comparada ao níveis apresentados por animais que consumiram dietas contendo 25\% de caseína (Vianna de Oliveira \& Fujimori, 1996a; Vianna de Oliveira \& de Angelis, 1996b; Vianna de Oliveira et al.,1998a; Vianna de Oliveira et al., 1998b; Vianna de Oliveira et al., 1999).

A adaptação à restrição energética crônica refletida nos ajustes ponderais, com uma aparente proteção do peso materno em detrimento do número de filhotes no pós-parto, difere dos resultados de outros estudos (Ferrari et al., 1992), mas parece ser o principal determinante dos resultados obtidos em relação à atividade da GGT e à concentração de GSH e proteína hepáticos.

Para finalizar e relacionando o aparente ganho ponderal e o metabolismo, é preciso citar que Álvarez-Ordás et al. (1992) ao estudarem o efeito da restrição alimentar na evolução da gestação em ratas, indicaram que o balanço de nitrogênio e a absorção de D-glicose não se alteraram nas mães desnutridas. Também demonstraram importantes correlações negativas entre micção e ganho em peso e/ou ingestão de água, sugerindo que durante a primeira metade da gestação haveria uma diminuição na excreção de nitrogênio urinário com conseqüente balanço nitrogenado positivo, sendo o nitrogênio armazenado nesta fase utilizado no final do processo gestacional. Esses autores concluíram ainda que a retenção de água, decorrente da micção reduzida, parece ser o principal fator responsável pelo peso aparentemente ganho pelas mães desnutridas.

Também em ratos adultos a privação parcial de alimentos parece aumentar o transporte líquido de açúcares, aumentando sua entrada através da membrana apical de enterócitos (Marciani et al. citado por Álvarez-Ordáz et al., 1992), compensando o desgaste desta manipulação dietética.

\section{REFERÊNCIAS BIBLIOGRÁFICAS}

ÁlVAREZ-ORDÁS, I., GUITIÉRREZ, J.M., CASADO, C., FERNÁNDEZ, S., MENÉNDEZ-PATTERSON, A. Effect of ma- 
ternal food restriction on the evolution of pregnancy in the rat. Revista Española de Fisiologia, Barcelona, v.48, n.4, p.277-284, 1992.

ATINMO, T., BALDIJÃO, C., POND, W.G., BARNES, R.H. The effect of dietary protein restriction on serum thyroxine levels of pregnant or growing swine. Journal of Nutrition, Philadelphia, v.108, n.9, p.1456-1533, 1978.

COMPORTI, M., MAELLARO, E., DEL BELLO, B., CASINI, A.F. Glutathione depletion: its effect on other antioxidant systems and hepatocelular damage. Xenobiotica, London, v.21, n.8, p.1067-1076, 1991.

COWARD, W.A., WHITEHEAD, R.G., LUNN, P.G. Reasons why hypoalbuminaemia may or may not appear in protein-energy malnutrition. British Journal of Nutrition, Cambridge, v.38, n.1, p.115-126, 1977.

DEAN, A.G., DEAN, J.A., BURTON, A.H., DICKER, R.C. Epi Info. Version 6. Atlanta : CDC/OMS, 1997. 586p.

FERRARI, F., GABRIELLI, P.R.M., MELLO, M.A.R. Restrição alimentar durante a gestação e suas implicações sobre o binômio mãe/feto: um modelo experimental utilizando ratas jovens e adultas. Alimentos e Nutrição, São Paulo, v.4, p.45-56, 1992.

GOSS, P.M., BRAY, T.M., NAGY, L.E. Regulation of hepatocyte glutathione by amino acid precursors and cAMP in protein - energy malnourished rats. Journal of Nutrition, Philadelphia, v.124, n.3, p.323-330, 1994.

HUM, S., KOSKI, K.G., HOFFER, L.J. Varied protein intake alters glutathione metabolism in rats. Journal of Nutrition, Philadelphia, v.122, n.10, p.2010-2018, 1992.

JACOBS, W.L.W. A colorimetric assay for $\gamma$ glutamyltranspeptidase. Clinica Chimica Acta, Amsterdam, v.31, p.175-179, 1971.

LOWRY, O.H., ROSEBROUGH, N.J., FARR, A.L., RANDALL, R.J. Protein measurement with the folin-phenol reagent. Journal of Biological Chemistry, Baltimore, v.193, n.1, p.265-275, 1951.

MEISTER, A. On the enzymology of amino transport. Science, New York, v.180, n.81, p.33-39, 1973.

PERSIJIN, J.P. et al. Colorimetric assay for $\gamma$-glutamyltranspeptidase. Clinica Chimica Acta, Amsterdam, v.35, p.239-240, 1971.

SAINZ, R.D., CALVERT, C.C., BALDWIN, R.L. Relationships among dietary protein feed intake and tissue protein turnover in lactating rats. Journal of Nutrition, Philadelphia, v.116, n.9, p.1820-1829, 1986.

SAVILLE, B. A scheme for the colorimetric determination of microgram amounts of thiols. Analyst, London, v.83, n.2, p.670-671, 1958.

SMITH, J.E., LUNN, P.G. Albumin-synthesizing capacity of hepatocytes isolated from rats fed diets differing in protein and energy content. Annals of Nutrition and Metabolism, Basel, v.28, n.5, p.281-287, 1984.

SZASZ, G. $\gamma$-glutamyltranspeptidase. In: BERGMEYER, H.U. (ed) Methods of enzymatic analysis. 2.ed. New York: Academic Press, 1974. v.2: p.715-719.

TATEISHI, N., HIGASHI, T., SHINYA, S., NARUSEA, A., SAKAMOTO, Y. Studies on the regulation of glutathione level in rat liver. Journal of Biochemistry, Tokyo, n.1, v.75, p.93-103, 1974.

TATEISHI, N. et al. Rat liver glutathione: possible role as a reservoir of cysteine. Journal of Nutrition, Philadelphia, v.107, n.1, p.51-61, 1977.

VIANNA DE OLIVEIRA, I.M., DE ANGELIS, R.C. Differential effects of protein restriction on gammaglutamyltranspeptidase [EC. 2.3.2.2] activity in young and mature rats. Brazilian Journal of Medical and Biological Research, Ribeirão Preto, v.29, n.2, p.213-217, 1996a.

VIANNA DE OLIVEIRA, I.M., FUJIMORI, E. Liver gamma-glutamyl trans-peptidase activity and glutathione levels in lactating rats and pups: effect of dietary protein quantity and feed intake. The Journal of Nutritional Biochemistry, Stoneham, v.7, n.2, p.93-98, 1996b.

VIANNA DE OLIVEIRA, I.M., DE ANGELIS, R.C., SILVA, L. Dietas à base de arroz e feijão aumentam a atividade plasmática e hepática da gama-glutamiltranspeptidase em ratos jovens. Archivos Latinoamericanos de Nutrición, Guatemala, 1998a. (No prelo).

VIANNA DE OLIVEIRA, I.M., SAKAUE, C., LIMA, A.R. Alterações na atividade da gama-glutamiltranspeptidase e nos níveis de glutationa em fígado de ratos submetidos a dietas deficientes em metionina. São Paulo : EEUSP, 1998b. 22p. (Resultados não publicados; Mimeografado).

VIANNA DE OLIVEIRA, FUJIMORI, E., PEREIRA, V.G., CASTRO, V.D. DL-methionine supplementation of rice and beans diets affects gamma-glutamytranspeptidase activity and glutathione content in livers of growing rats. Brazilian Journal of Medical and Biological Research, Ribeirão Preto, v.32, n.4, p.483-488, 1999.

Recebido para publicação em 8 de setembro de 1998 e aceito em 27 de abril de 1999. 